\title{
OCCUPATIONAL BURNOUT AMONG PUBLIC MEDICAL OFFICERS DURING THE EARLY STAGE OF COVID-19 PANDEMIC IN KOTA KINABALU, SABAH
}

\author{
Ahmad Hazim Mohammad ${ }^{1}$, Shamsul Bahari Shamsudin ${ }^{1}$, Nornazirah Ahmad Kamarudin ${ }^{1}$, Lim Mei Ching ${ }^{1}$, \\ Ahmad Syukri Radzran ${ }^{1}$, Muhamad Hanif Mohd Deris ${ }^{1}$ and Mohamad Hafiz Mukhsam ${ }^{1}$ \\ ${ }^{1}$ Department of Community and Family Medicine, Faculty of Medicine and Health Sciences, University Malaysia Sabah, \\ 88400, Kota Kinabalu, Sabah, Malaysia.
}

Corresponding Author: Shamsul Bahari Shamsudin

Email: shamsul@ums.edu.my

\begin{abstract}
Burnout syndrome has affected many doctors globally, and this problem has caused various negative impacts on public health services such as reduced productivity and reduced quality care of patients. Various factors were associated with burnout among doctors, but the factors vary in different countries. This study aimed to investigate the prevalence and associated risk factors of burnout among public service medical officers in Kota Kinabalu, Sabah, who were involved in combating the Covid-19 outbreaks. A cross-sectional study involving 201 medical officers working in all government hospitals and health clinics was carried out. Using the Copenhagen Burnout Inventory (CBI), the prevalence of personalrelated and work-related burnout were $61.2 \%$ and $48.8 \%$ respectively, while the prevalence of client-related burnout was $39.8 \%$. Working in different medical departments and the length of working experience were the significant associated risk factors of burnout among the doctors. Meanwhile, other predictors were found not to be significantly associated with the prevalence of burnout. The prevalence of burnout among medical officers in Kota Kinabalu was relatively high especially among the less experienced doctors and among those who work in surgical based departments, and these issues require multilevel interventions which involve policymakers in the Ministry of Health, organizational and administrative managers at the various health departments and the medical officers themselves.
\end{abstract}

Keyword: Occupational burnout, public health, Covid-19, doctors

\section{INTRODUCTION}

Occupational burnout among doctors is one of the major public health issues since it has a serious impact on the health care system as well as the mental and physical wellbeing of the doctors themselves ${ }^{1}$. Burnout has resulted in a decreased level of productivity ${ }^{2}$ as well as an increase in medical errors which may directly or indirectly affect the quality of care for the patients ${ }^{2,3}$. If this burnout problem is not resolved now, this later will lead to an increase of financial burden and failure in the health care system of a country ${ }^{4,5}$. Unfortunately, due to unbearable stress, there were reports of doctors committing suicide ${ }^{5}$. Chronic and poorly managed stress not only affected the mental health of the doctors but also predispose them to cardiovascular diseases ${ }^{6}$. Physically drained doctors will experience fatigue that can result in a motor vehicle accidents, especially during driving ${ }^{7}$.

Burnout among health care personnel was first noticed by Herbert Freudenberger ${ }^{8}$. Burnout is defined as a psychological syndrome resulting from chronic job-related stress, which is characterized by three dimensions: overwhelming emotional exhaustion; feelings of cynicism and detachment from the job; and a sense of ineffectiveness and low level of personal accomplishment ${ }^{9}$. There is another concept of burnout which is described with a broader aspect that not only focuses on the person but also includes environmental or other related factors which are characterized by personal-related burnout occurring simultaneously with workrelated burnout and client-related burnout ${ }^{10}$.

Burnouts among doctors were not only common in high-income countries, but also affected doctors in low and middle-income countries, including Malaysia. There are not many studies yet on burnout among medical officers in Malaysia, but a recent study conducted in 2019 reported that one in four medical officers in the hospital experienced burnout. These medical officers were part of an important workforce in providing the highest quality of care for the patients, thus, it is essential to look after their physical and mental wellbeing ${ }^{11}$.

There are still many gaps in understanding the associated risk factors of burnout, hence, the main objectives of this study were to identify the prevalence of burnout among government medical officers working in Kota Kinabalu and to investigate the associated risk factors among them, including the primary health care doctors. It was hoped that this study would provide a better insight into improving their working environment, as well as their mental and physical 
well beings, especially when facing a major medical crisis such as the Covid-19 pandemic.

\section{MATERIAL \& METHOD}

\section{Study Design}

The cross-sectional study was conducted from March 2020 to April 2020 involving medical officers working in all government hospitals, district health offices, and health clinics in Kota Kinabalu during the early stages of the Covid-19 pandemic.

\section{Participants}

With the prevalence of burnout among medical officers in one of the tertiary hospitals in Malaysia in previous literature was $25.6 \%{ }^{11}$, \%, 95\% of confident interval and $5 \%$ of margin of error allowed, the total of sample supposedly was 375 after considering $80 \%$ response rate. Doctors that were invited were the medical officers in government hospitals, district health office, and health clinics in Kota Kinabalu. Specialist or medical officer in private practices were not included in the study.

\section{Study Instrument \& Data Collection}

The questionnaire was prepared using Google Forms, a survey administration software, which included the sociodemographic questionnaire and Copenhagen Burnout Inventory (CBI) as the assessment tool. The $\mathrm{CBI}$ consists of three parts with a total of 19 items. Part one assesses personal burnout and has six questions. Part two assesses work-related burnout and contains seven questions. Part three assesses client-related burnout and consists of six questions. Interpretation is based on the average score of the items tested in each part. If the average score of the items in each part is more than 50 , the person is at a high risk of burnout.

\section{Data Analysis}

Internal consistency of the $\mathrm{CBI}$ and the results of the reliability test are presented with Cronbach's alpha score. Analyses were done using IBM Statistical Packages for Social Sciences (SPSS) version 26.0. Descriptive data were expressed in frequency for qualitative data, while quantitative data were expressed in mean with standard deviation. For all hypotheses, chi-square test and simple logistic regression were conducted to determine the association between prevalence of burnout and the risk factors. Lastly, multivariate analysis was conducted to control the confounders in which the results were expressed in odds ratio (OR) with $95 \%$ confidence interval. A p-value of $<0.05$ was considered statistically significant.

\section{RESULTS}

A total of 201 doctors agreed to participate in the study, but the response rate was only $55.4 \%$. Table 1 displays the sociodemographic characteristics of the respondents of this study. The reliability test score, done with Cronbach's alpha, was 0.955. Table 2 displays the prevalence of burnout among government medical officers in Kota Kinabalu. The average scores for personal-related burnout, work-related burnout, and client-related burnout were $53.48(S D=19.41), 47.37(S D=21.40)$, and $43.12(S D=20.92)$ respectively.

Based on chi-square analysis and independent ttest as shown in Table 3 , the only significant associations were between the medical department with personal-related and workrelated burnout, as well as between working experience with personal-related and clientrelated burnout.

As displayed in Table 4, there were strong associations among working in different medical departments, length of working experience, and race of respondents with burnout. These significant factors were further analysed with multivariate analysis which was presented in Table 5. Working in different medical departments and the length of working experience were noted as significant associated risk factors of burnout among the doctors. 
Table 1. Sociodemographic characteristics of government medical officers

\begin{tabular}{|c|c|c|c|}
\hline Variables & Distribution & Total (\%) & Mean (SD) \\
\hline Age & & & $31.1 \pm 3.28$ \\
\hline \multirow[t]{2}{*}{ Sex } & Female & $120(59.7)$ & \\
\hline & Male & $81(40.3)$ & \\
\hline \multirow[t]{4}{*}{ Race } & Malay & $59(29.4)$ & \\
\hline & Chinese & $60(29.9)$ & \\
\hline & Indians & $34(16.9)$ & \\
\hline & Sabah \& Sarawak Bumi & $48(23.9)$ & \\
\hline \multirow[t]{2}{*}{ Marital status } & Single & $129(64.2)$ & \\
\hline & Married & $72(35.8)$ & \\
\hline \multirow[t]{2}{*}{ Having child } & No & $160(79.6)$ & \\
\hline & Yes & $41(20.4)$ & \\
\hline \multirow[t]{2}{*}{ Workplace } & Hospital based & $163(80.1)$ & \\
\hline & Community based & $38(19.9)$ & \\
\hline \multirow[t]{3}{*}{ Departments } & Medical based & $115(57.2)$ & \\
\hline & Surgical based & $48(23.9)$ & \\
\hline & Primary health care & $38(19.9)$ & \\
\hline \multirow[t]{2}{*}{ Origin } & Sabah & $70(34.8)$ & \\
\hline & Other States & $131(65.2)$ & \\
\hline \multirow[t]{2}{*}{ Undergraduate } & Local & $110(54.7)$ & \\
\hline & Overseas & $91(45.3)$ & \\
\hline \multirow[t]{2}{*}{ Working experiences } & $<5$ years & $116(57.7)$ & \\
\hline & $\geq 5$ years & $85(42.3)$ & \\
\hline \multirow[t]{2}{*}{ Commuting time } & $<20 \min$ & $164(81.6)$ & \\
\hline & $\geq 20 \min$ & $37(18.4)$ & \\
\hline \multirow[t]{2}{*}{ Working hours per week } & $\leq 60$ & $45(22.4)$ & $67.68(13.89)$ \\
\hline & $>60$ & $156(77.6)$ & \\
\hline \multirow[t]{2}{*}{ Working night shift } & No & $51(25.4)$ & \\
\hline & Yes & $150(74.6)$ & \\
\hline
\end{tabular}


Table 2. Prevalence of burnout

\begin{tabular}{lc}
\hline Scope of Burnout & Prevalence \\
\hline Personal-related Burnout & 61.2 \\
Work-related Burnout & 48.8 \\
Client-related Burnout & 39.8 \\
\hline $\mathrm{N}=201$ & \\
\hline
\end{tabular}

Table 3. Association of sociodemographic factors with burnout

\begin{tabular}{|c|c|c|c|}
\hline Variables & $\begin{array}{c}\text { Personal-related burnout } \\
\mathrm{t} \text { ( } \mathrm{p} \text {-value) }\end{array}$ & $\begin{array}{c}\text { Work-related burnout } \\
\mathrm{t} \text { (p-value) }\end{array}$ & $\begin{array}{c}\text { Client-related burnout } \\
\text { t ( } p \text {-value) }\end{array}$ \\
\hline Age & $1.426(0.155)$ & $0.634(0.527)$ & $1.097(0.274)$ \\
\hline & $\mathrm{X}^{2}$ (p-value) & $\mathrm{X}^{2}$ (p-value) & $\mathrm{X}^{2}$ (p-value) \\
\hline Sex & $0.028(0.867)$ & $0.188(0.665)$ & $0.005(0.944)$ \\
\hline Race & $6.324(0.097)$ & $6.171(0.104)$ & $6.597(0.086)$ \\
\hline Marital Status & $0.853(0.356)$ & $0.001(0.975)$ & $1.208(0.272)$ \\
\hline Having child & $0.001(0.974)$ & $0.125(0.724)$ & $0.013(0.909)$ \\
\hline Origin & $0.432(0.511)$ & $0.859(0.354)$ & $3.448(0.063)$ \\
\hline Undergraduate & $0.610(0.435)$ & $0.032(0.858)$ & $0.125(0.724)$ \\
\hline Workplace & $0.694(0.405)$ & $0.303(0.582)$ & $0.171(0.679)$ \\
\hline Medical dept & $6.160(0.046)$ * & $11.433(0.003)$ * & $1.271(0.530)$ \\
\hline Working exp & $5.515(0.019)$ * & $1.610(0.204)$ & $5.217(0.022)$ * \\
\hline Commuting time & $0.776(0.378)$ & $0.509(0.475)$ & $0.715(0.398)$ \\
\hline Working hours & $1.509(0.219)$ & $0.991(0.320)$ & $0.436(0.509)$ \\
\hline Night shift & $1.960(0.162)$ & $3.618(0.057)$ & $0.579(0.447)$ \\
\hline
\end{tabular}

*Significant $p<0.05 . N=20$ 
Table 4. Simple logistic regression analysis of sociodemographic factors

\begin{tabular}{|c|c|c|c|c|c|c|}
\hline \multirow[t]{2}{*}{ Variables } & \multicolumn{2}{|c|}{ Personal-related burnout } & \multicolumn{2}{|c|}{ Work-related burnout } & \multicolumn{2}{|c|}{ Client-related burnout } \\
\hline & OR $(95 \% \mathrm{Cl})$ & p-value & OR $(95 \% \mathrm{Cl})$ & $\mathrm{p}$-value & OR $(95 \% \mathrm{Cl})$ & p-value \\
\hline Age & $0.94(0.86,1.03)$ & 0.159 & $0.97(0.89,1.06)$ & 0.526 & $0.95(0.87,1.04)$ & 0.275 \\
\hline Sex & $1.05(0.59,1.87)$ & 0.867 & $0.88(0.50,1.55)$ & 0.665 & $1.02(0.57,1.82)$ & 0.944 \\
\hline Marital Status & $0.76(0.42,1.37)$ & 0.356 & $0.99(0.56,1.76)$ & 0.975 & $0.72(0.39,1.30)$ & 0.273 \\
\hline Having child & $1.01(0.50,2.04)$ & 0.974 & $0.88(0.45,1.76)$ & 0.724 & $1.04(0.52,2.10)$ & 0.909 \\
\hline Origin & $0.82(0.45,1.49)$ & 0.511 & $1.32(0.74,2.36)$ & 0.354 & $0.57(0.32,1.03)$ & 0.064 \\
\hline Undergraduate & $0.80(0.45,1.41)$ & 0.435 & $1.05(0.60,1.83)$ & 0.858 & $0.90(0.51,1.59)$ & 0.724 \\
\hline Workplace & $1.35(0.66,2.76)$ & 0.406 & $1.22(0.60,2.48)$ & 0.582 & $1.17(0.56,2.42)$ & 0.679 \\
\hline Working exp & $0.50(0.28,0.90)$ & $0.020^{*}$ & $0.70(0.40,1.22)$ & 0.205 & $0.51(0.28,0.91)$ & $0.023^{*}$ \\
\hline Commuting & $1.40(0.66,2.99)$ & 0.380 & $1.30(0.63,2.65)$ & 0.476 & $1.36(0.66,2.80)$ & 0.399 \\
\hline Working hours & $1.52(0.78,2.97)$ & 0.221 & $1.40(0.72,2.74)$ & 0.321 & $1.26(0.63,2.51)$ & 0.509 \\
\hline Night shift & $1.58(0.83,3.00)$ & 0.163 & $1.87(0.98,3.60)$ & 0.059 & $1.29(0.67,2.50)$ & 0.447 \\
\hline \multicolumn{7}{|l|}{ Race } \\
\hline Malay & $0.85(0.41,1.74)$ & 0.651 & $0.90(0.44,1.86)$ & 0.773 & $1.48(0.70,3.14)$ & 0.307 \\
\hline Indian & $2.49(0.97,6.38)$ & 0.058 & $2.56(1.06,6.16)$ & $0.037^{*}$ & $1.03(0.42,2.54)$ & 0.945 \\
\hline Sabah \& Sarawak Bumi & $1.53(0.70,3.36)$ & 0.291 & $1.12(0.53,2.41)$ & 0.763 & $2.55(1.16,5.60)$ & $0.020^{*}$ \\
\hline \multicolumn{7}{|l|}{ Medical Dept } \\
\hline Primary Health & $0.38(0.15,0.96)$ & $0.040 *$ & $0.34(0.14,0.84)$ & $0.019 *$ & $0.66(0.28,1.59)$ & 0.356 \\
\hline Medical Based & $0.40(0.19,0.87)$ & $0.021^{*}$ & $0.30(0.15,0.62)$ & $0.001^{*}$ & $0.69(0.35,1.38)$ & 0.297 \\
\hline
\end{tabular}

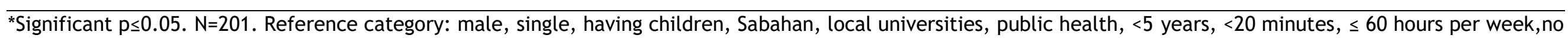
night shift 
Table 5. Multivariate analysis of burnout among medical officers

\begin{tabular}{|c|c|c|c|c|c|}
\hline \multicolumn{6}{|c|}{ Personal-related burnout } \\
\hline Variables & B & SE & OR & $95 \% \mathrm{Cl}$ & p-value \\
\hline \multicolumn{6}{|l|}{ Medical Dept } \\
\hline Medical Based & 1.293 & 0.559 & 3.643 & $(1.218,10.896)$ & $0.021^{*}$ \\
\hline Surgical Based & 1.455 & 0.658 & 4.286 & $(1.179,15.572)$ & $0.027^{*}$ \\
\hline \multicolumn{6}{|l|}{ Working Exp } \\
\hline$\geq 5$ years & -1.629 & 0.412 & 0.196 & $(0.087,0.440)$ & $0.000^{*}$ \\
\hline \multicolumn{6}{|l|}{ Interaction } \\
\hline (Primary) $(\geq 5$ years $)$ & 2.679 & 0.792 & 14.571 & $(3.088,68.767)$ & $0.001^{*}$ \\
\hline (Surgical)( $\geq 5$ years) & 1.852 & 0.823 & 6.375 & $(1.271,31.968)$ & $0.024^{*}$ \\
\hline \multicolumn{6}{|c|}{ Classification table 70.1\%. Nagelkerke R Squared 0.164} \\
\hline \multicolumn{6}{|c|}{ Work-related burnout } \\
\hline Variables & B & SE & OR & $95 \% \mathrm{Cl}$ & p-value \\
\hline \multicolumn{6}{|l|}{ Medical Dept } \\
\hline Medical Based & -1.118 & 0.377 & 0.327 & $(0.156,0.685)$ & $0.003^{*}$ \\
\hline Primary Health & -1.007 & 0.469 & 0.365 & $(0.146,0.917)$ & $0.032 *$ \\
\hline \multicolumn{6}{|c|}{ Classification table $61.7 \%$. Nagelkerke R Squared 0.101.} \\
\hline \multicolumn{6}{|c|}{ Client-related burnout } \\
\hline Variables & B & SE & OR & $95 \% \mathrm{Cl}$ & p-value \\
\hline \multicolumn{6}{|l|}{ Race } \\
\hline Sabah \& Sarawak Bumi & 1.102 & 0.416 & 3.010 & $(1.331,6.805)$ & $0.008 *$ \\
\hline \multicolumn{6}{|l|}{ Working Exp } \\
\hline$\geq 5$ years & -0.809 & 0.317 & 0.445 & $(0.239,0.829)$ & $0.011^{*}$ \\
\hline
\end{tabular}

*Significant $p \leq 0.05 . \mathrm{N}=201$ 


\section{DISCUSSION}

Among the government medical officers in Kota Kinabalu, $61.2 \%$ experienced personal-related burnout, $48.8 \%$ of the respondents experienced work-related burnout, whereas $39.8 \%$ experienced client-related burnout. The prevalence of burnout among doctors in this study was higher compared to doctors in Lithuania ${ }^{12}$ as well as doctors in Sri Lanka ${ }^{13}$. The prevalence of burnout among doctors varied in different countries due to the variability of risk factors involved such as the workload, the country's healthcare system, and the assessment tool being used.

This study found that working in different medical departments and the length of working experience were significant predictors for burnout among the medical officers. Surgicalbased doctors were found to have the highest prevalence of all the burnout scopes. The doctors in both medical-based and surgical-based departments were three times to four times more likely to experience personal-related burnout as compared to doctors in primary health care.

Doctors in surgical departments were three times more likely to experience work-related burnout compared to doctors working in medical departments and primary health care. The prevalence of burnout varies depending on the sociodemographic factors as well as the workload in a country, for example, in the United States; based on Medscape survey in 2020, the prevalence of burnout is highest among doctors in medicalbased departments whereas general surgery only reported $35 \%$ of prevalence. Public health physicians were reported to have the lowest prevalence of burnout ${ }^{14}$.

In the meta-analysis conducted to review the prevalence of burnout among medical and surgical residences across many countries in Asia, Europe, North America, and Africa, the overall differences in prevalence between surgical residents and medical residents were not statistically significant, but the prevalence was slightly higher among surgical residents, and family medicine doctors have the lowest prevalence of burnout compared to other groups which were similar with the findings in this study ${ }^{15}$. The finding in this study was also in line with a systematic review and meta-analysis of burnout syndrome among 4664 doctors in various countries ${ }^{16}$.

Doctors with less than five years of working experience were five times more likely to experience personal-related burnout compared to the more experienced doctors. Furthermore, the less experienced doctors in this study also were two times more likely to experience client-related burnout. A recent study stated that a younger and less experienced doctor had a 30\% higher chance of burnout ${ }^{17}$. A similar finding was reported among the primary health care doctors in Iran where the less experienced doctors were nine times more likely to experience burnout ${ }^{18}$.

Although age was not significantly associated in this study, younger doctors were commonly at higher risk of burnout as shown in a systematic review in the Middle East which included doctors in Saudi Arabia, Turkey, and Israel ${ }^{19}$. Another systematic review also described that junior doctors are at higher risk of burnout due to lack of experience ${ }^{20}$. There was no significant difference between male and female doctors in this study, however, most of the other studies showed that female doctors were at higher risk of burnout. In a study among family physicians, the prevalence of burnout was higher in females ${ }^{21}$. According to a systematic review, female physicians were at higher risk of burnout most likely due to difficulties in balancing between work demands and family responsibilities ${ }^{22}$. This situation also was seen among healthcare provider in Italy and Japan ${ }^{23,24}$

The race was not significantly associated with personal-related and work-related burnout, but interestingly, after further analysis of clientrelated burnout among the races, it was reported that Sabah and Sarawak Bumiputera doctors were noted to be three times more likely to experience client-related burnout compared to the Chinese doctors. The Sabah and Sarawak Bumiputera doctors were minority groups in this medical field, hence, they had difficulties in coping with the working environment and the high expectations from patients ${ }^{25}$.

Marital status was not significantly associated with the prevalence of burnout, but the prevalence was slightly higher among single doctors. The finding contradicted the studies done among health care professionals in Ghana and Portugal which reported that the prevalence of burnout was higher among married doctors ${ }^{26,27}$. There was also no significant association between having children and the prevalence of burnout. However, a study in Saudi Arabia indicated that having children was one of the significant predictors of burnout ${ }^{28}$ which was similar to a study in Hungary which pointed out that the number of children had a significant positive correlation with burnout, especially among female doctors ${ }^{29}$.

Although there was a study among doctors with less than five years' experience working in a tertiary hospital which reported that overseas graduates were two times more likely to experience work-related stress ${ }^{30}$, there were no differences between the doctors' place of origin and place of graduation with regards to the prevalence of burnout in this study. According to a systematic review, overseas graduates might have difficulty adapting to a different health care system. They were found to be struggling if they 
had previously studied in less developed countries. Nonetheless, this struggle usually only happened at the early stages of their careers, and the doctors would already be able to adapt to the current working environment as time went by ${ }^{31}$.

There were no significant differences in the prevalence of burnout for all scopes among the different workplace groups, but the prevalence was slightly higher among medical officers working in hospitals which was similar with research conducted in $\operatorname{Iran}^{18}$. Even though commuting time was not significantly associated with burnout, the prevalence of each scope of burnout was slightly higher among medical officers who travel for more than 20 minutes to the workplace. This finding was in accordance with the findings in a study done in Quebec, Canada, which reported a strong correlation between commuting stress and the likelihood of burnout ${ }^{32}$.

Doctors with more than 60 working hours per week and doing night shift would be expected to have a significantly much higher prevalence of burnout however in this study, however, there was no significant differences in the prevalence of burnout among them. The finding was contradicted with other studies done in various countries where long working hours and night shift were significantly associated with burnout ${ }^{33-35}$. The contradiction might be due to that those medical officers had already been able to cope with the long working hours and night shift as they have been experienced during their housemanship training years ${ }^{36}$.

The response rate was less than satisfactory as the data collection was conducted online, and most of the doctors were busy in the management of Covid-19 patients. We also were advised to keep the frequency of the reminder at the minimum so we would not disturb them as the pandemic worsen hence, we had to shorten the period of data collection. Lastly, the results in this study might not be able to be generalized among other healthcare workers as their job scopes were different however it can provide a snapshot of the estimation of the prevalence of burnout among the medical officers with the identical workplace setting in Malaysia.

\section{CONCLUSION}

The findings in this study demonstrated that the prevalence of burnout among doctors in Sabah was high especially at the early stages of the Covid-19 pandemic. The significant predictors for burnout were working in different medical departments and the length of working experience. It is essential to promote a healthy working environment to reduce the risk of burnout which can be done by reviewing the current policies and reassessing workforce availability. All these require involvement from every level of management, particularly the policymakers, the board of hospital directors, the head of departments, and the doctors themselves.

\section{ACKNOWLEDGEMENT}

The authors would like to thank the DirectorGeneral of Health Malaysia for his permission to publish this article. We also would like to acknowledge the cooperation given by the Sabah State Health Department, all directors, department heads and medical officers in Queen Elizabeth Hospital, Queen Elizabeth Hospital 2, Sabah Women and Children's Hospital and Kota Kinabalu District Health Office.

Funding: This research was funded by University Malaysia Sabah Great Grant (UMSGreat) with project code number GUG0470-1/2020.

Conflict of Interest: The authors declared no conflict of interest.

Ethical Clearance: This study has received the ethical clearance from the Ethical Committee of the Faculty of Medical and Health Science, UMS, with approval code JKEtika 1/20 (6) and Medical Research Ethical Committee of Ministry of Health Malaysia with approval number NMRR-19-372052397 (IIR). Respondents' informed consents were obtained before they proceeded with filling up the sociodemographic data and answering the questionnaires online.

\section{REFERENCES}

1. Sibeoni, J. et al. Physicians' Perspectives About Burnout: a Systematic Review and Metasynthesis. 1578-1590 (2019). doi:10.1007/s11606-019-05062-y

2. West, C. P., Dyrbye, L. N. \& Shanafelt, T. D. Physician burnout: contributors, consequences and solutions. J. Intern. Med. 283, 516-529 (2018).

3. Scheepers, R., Silkens, M., van den Berg, J. \& Lombarts, K. Associations between job demands, job resources and patientrelated burnout among physicians: results from a multicentre observational study. BMJ Open 10, e038466 (2020).

4. Patel, R. S., Sekhri, S., Bhimanadham, N. N., Imran, S. \& Hossain, S. A Review on Strategies to Manage Physician Burnout. Cureus 11, 3-12 (2019).

5. Yates, S. W. Physician Stress and Burnout. Am. J. Med. 133, 160-164 (2020).

6. Morales, J. et al. Stress and autonomic response to sleep deprivation in medical residents: A comparative cross-sectional study. 1-14 (2019). 
7. Mak, N. T., Li, J. \& Wiseman, S. M. Resident Physicians are at Increased Risk for Dangerous Driving after Extendedduration Work Shifts: A Systematic Review. 11, (2019).

8. Reith, T. P. Burnout in United States Healthcare Professionals: A Narrative Review. Cureus 10, (2018).

9. Maslach, C. \& Leiter, M. P. Understanding the burnout experience: recent research and its implications for psychiatry. 103-111 (2016).

10. Wolfshohl, J. A. et al. Association Between Empathy and Burnout Among Emergency Medicine Physicians. J. Clin. Med. Res. 11, 532-538 (2019).

11. Ali, N. F., Jannah, N. \& Raduan, N. A cEBs2019Langkawilsland Burnout and Coping Skills amongst Medical Officers : A study in a tertiary hospital in Malaysia. Environ. Proc. J. 4, 141 (2019).

12. Žutautienè, R. The prevalence of burnout and its associations with psychosocial work environment among kaunas region (Lithuania) hospitals' physicians. Int. J. Environ. Res. Public Health 17, (2020).

13. Fernando, B. M. S. \& Samaranayake, D. L. Burnout among postgraduate doctors in Colombo: prevalence, associated factors and association with self-reported patient care. BMC Med. Educ. 19, 373 (2019).

14. Kane, L. Medscape National Physician Burnout \& Suicide Report 2020: The Generational Divide. (2020). Available at: https: / / www.medscape.com/slideshow/2 020-lifestyle-burnout-6012460.

15. Low, Z. X., Yeo, K. A. \& Sharma, V. K. Prevalence of Burnout in Medical and Surgical Residents: A Meta-Analysis. 1-22 (2019).

16. Rodrigues, $\mathrm{H}$. et al. Burnout syndrome among medical residents: A systematic review and meta-analysis. PLoS One 13, 117 (2018).

17. Carmen, M. G. et al. Trends and Factors Associated With Physician Burnout at a Multispecialty Academic Faculty Practice Organization. 2, 1-10 (2019).

18. Zarei, E., Ahmadi, F. \& Sial, M. S. Prevalence of Burnout among Primary Health Care Sta ff and Its Predictors: A Study in Iran. (2019).

19. Chemali, Z., Ezzeddine, F. L. \& Gelaye, B.
Burnout among healthcare providers in the complex environment of the Middle East : a systematic review. 1-21 (2019).

20. Patel, R. S., Bachu, R., Adikey, A., Malik, M. \& Shah, M. Factors related to physician burnout and its consequences: A review. Behav. Sci. (Basel). 8, (2018).

21. Eden, A. R., Jabbarpour, Y. \& Morgan, Z. J. Burnout Among Family Physicians by Gender and Age. 1247, 355-356 (2020).

22. Azam, K., Khan, A. \& Alam, M. T. Causes and Adverse Impact of Physician Burnout: 27, 495-501 (2017).

23. Lasalvia, A. et al. Levels of burn- - out among healthcare workers during the COVID-19 pandemic and their associated factors: a sectional study in a tertiary hospital of a highly burdened area of. 1-12 (2021). doi:10.1136/bmjopen-2020045127

24. Matsuo, T., Kobayashi, D., Taki, F., Sakamoto, F. \& Uehara, Y. Prevalence of Health Care Worker Burnout During the Coronavirus Disease 2019 ( COVID-19) Pandemic in Japan. 2019, 2019-2022 (2020).

25. Garcia, L. C. et al. Burnout, Depression, Career Satisfaction, and Work-Life Integration by Physician Race / Ethnicity. 1-13 (2020). doi:10.1001/jamanetworkopen.2020.1276 2

26. Odonkor, S. T. Burnout among Healthcare Professionals in Ghana: A Critical Assessment. 2020, (2020).

27. Duarte, I. et al. Burnout among Portuguese healthcare workers during the COVID-19 pandemic. BMC Public Health 20, 1-10 (2020).

28. Marzouki, $\mathrm{H}$. et al. Burnout and job satisfaction among physicians in a Saudi tertiary care center: a cross-sectional study. 3, 990-997 (2019).

29. Adam, S., Mohos, A. \& Kalabay, L. Potential correlates of burnout among general practitioners and residents in Hungary: the significant role of gender , age , dependant care and experience. 1-10 (2018).

30. Minn, Y. C. \& Fei, S. H. Psychological morbidities amongst house officers in sarawak general hospital kuching. Med. J. Malaysia 74, 307-311 (2019). 
31. Motala, M. I. \& Wyk, J. M. Van. Experiences of foreign medical graduates ( FMGs), international medical graduates ( IMGs) and overseas trained graduates ( OTGs ) on entering developing or middle- income countries like South Africa: a scoping review. (2019).

32. Barreck, A. A correlation exists between commuting stress factors and the likelihood of suffering from burnout. (2015).

33. Geng, H. et al. High rate of burnout among residents under standardized residency training in a tertiary teaching hospital of middle China: Results from a crosssectional survey. Medicine (Baltimore).
99, e20901 (2020).

34. Ng, A. P. P., Chin, W. Y., Wan, E. Y. F., Chen, J. \& Lau, C. S. Prevalence and severity of burnout in Hong Kong doctors up to 20 years post-graduation: A crosssectional study. BMJ Open 10, 1-10 (2020).

35. Alrawashdeh, H. M. et al. Occupational Burnout and Job Satisfaction Among Physicians in Times of COVID-19 Crisis : A Convergent Parallel Mixed-Method Study. 1-30 (2020).

36. O'Dowd, E. et al. Stress, coping, and psychological resilience among physicians. BMC Health Serv. Res. 18, 1-11 (2018). 